\title{
Efeito do neem (Azadirachta Indica) no controle de nematódeos gastrintestinais em ovinos suplementados a pasto no período seco
}

\section{Neem (Azadirachta Indica) effect in gastrointestinal nematodes control in supplemented sheep during dry season grazing}

\author{
Michelle Igarashi ${ }^{1 *}$; Daniel Marino Guedes de Carvalho²; \\ Felipe Camargo Bucci ${ }^{3}$; Yuri Miranda ${ }^{4}$; Zaori Marques Rodrigues ${ }^{4}$; \\ Milena Campos Ferreira Almeida ${ }^{4}$; Mauricio Nobuyuki Miyashita Piona ${ }^{5}$
}

\section{Resumo}

Avaliou-se o efeito de extratos de Azadirachta indica (Neem) sobre a resposta produtiva e o controle de nematódeos gastrintestinais em ovinos Santa Inês mantidos em pastagem no período seco. Vinte e quatro ovinos foram divididos em três tratamentos: SP - Controle (Animais recebendo suplemento protéico); SP - Óleo (Animais recebendo suplemento protéico e extrato de óleo de Neem) e SP - Folha (Animais recebendo suplemento protéico e folhas secas de Neem). Os animais receberam diariamente o suplemento protéico, enquanto que o óleo e as folhas foram ofertados em intervalos de 15 dias, totalizando 4 doses ministradas. A cada dia de fornecimento do óleo e folhas, amostras de fezes foram colhidas (dias $0,15,30,45,60)$ para contagem de ovos por gramas de fezes (OPG) e posterior cultivo de larvas para a identificação dos gêneros. A suplementação protéica influenciou diretamente na diminuição dos ovos de nematódeos por grama de fezes dos ovinos (OPG) mantidos em pastagens de baixa qualidade, conseqüentemente trazendo benefícios no controle das verminoses. A. indica presente no óleo e nas folhas não acarretou diferença estatística entre os tratamentos quando comparada aos animais recebendo apenas o suplemento proteico. A associação dos derivados do Neem com a suplementação protéica não foi capaz de aumentar o desempenho dos animais mesmo com os índices de OPG diminuídos, evidenciando assim a capacidade da suplementação protéica apresentar maiores efeitos sobre o controle das endoparasitoses em relação ao uso das associações proteínas e folhas de Neem ou proteínas e óleo de Neem.

Palavras-chave: Controle de nematódeos, ovinos, suplementação, proteína

\begin{abstract}
The aim of this study was to evaluated the effect of Azadirachta indica (Neem) extracts upon the productive response and control of gastrointestinal nematodes in Santa Inês sheep during the dry season grazing. Twenty four sheep, were divided in three groups according to the following treatments: SP Control (Animals receiving protein supplement); SP- Oil (Animals receiving protein supplement and Neem oil extract) and SP - Leaf (Animals receiving protein supplement and Neem dry leaves). The animals received daily protein supplement, while the oil and the dry leaves treatments were offered at interval of 15 days, a total of 4 doses ministred. Each day of supply of oil and leaves, feces samples were

${ }^{1}$ Prof. da Universidade de Cuiabá, UNIC, Cuiabá, MT. E-mail: michelle.igarashi@gmail.com

${ }^{2}$ Prof. da Universidade Federal do Amazonas, UFAM, Parintins, AM. E-mail: danielguedes14@yahoo.com.br

${ }^{3}$ Médico Veterinário, Empresa NUTRIDEAL, Cuiabá, MT. E-mail: felbugni@hotmail.com

${ }^{4}$ Discente(s) da UNIC, Cuiabá, MT. E-mail: yuri_dekinha@hotmail.com; zaori.marques@gmail.com; milena_camposf@hotmail.

${ }^{5}$ Gerente Técnico e comercial, Nutrideal Nutrição Animal, Cuiabá, MT. E-mail: mauricio@nutrideal.com.br
\end{abstract} com

* Autor para correspondência 
collected (day $0,15,30,45,60)$ for egg count per gram and subsequent larval cultivation for identifying genres. The protein supplement directly influenced the reduction of nematode eggs obtained per gram of feces (FEC) of sheep on quality grazing, consequently bringing benefits for the worms control. $A$ indica present in the oil and leaves did not obtain any statistical difference between the treatments when compared to the animals receiving only protein supplement. The association of Neem derivatives with protein supplement have not been able to increase animal performance even after decreasing the rates of FEC, showing that protein supplement were more able to provide effects on internal parasites control, when compared with to Neem oil or Neem dry leaves treatments.

Key words: Nematode control, ovine, supplementation, protein

\section{Introdução}

A infecção por nematódeos gastrintestinais é o principal problema sanitário da criação de pequenos ruminantes no Brasil. Um dos parasitos de ovinos mais importantes e prevalentes em diversos microclimas de pastagens é o Haemochus contortus (CARNEIRO; ALMARANTE, 2008), ocasionando perdas produtivas como retardo no crescimento e mortalidade especialmente de jovens e fêmeas no periparto (MOTA et al., 2003; TAVARES et al., 2009). Com o objetivo de se controlar essas infecções parasitárias, gerou-se um aumento na demanda de diversos anti-helmínticos, porém o uso indiscriminado destes originou a seleção de parasitos resistentes (MOLENTO, 2004).

Devido à resistência dos nematódeos de ovinos às drogas anti-helmínticas, torna-se necessário a busca de novas alternativas no controle das endoparasitoses. Dentre elas inclui-se o uso de fitoterápicos com efeito anti-helmíntico (VIEIRA, 2007). Extratos de A. indica (Neem) destacamse pela sua eficiência no controle de nematódeos gastrintestinais em pequenos ruminantes, principalmente de substâncias obtidas das folhas e sementes (CHAGAS; VIEIRA, 2007).

A prática de suplementação alimentar é outro fator que permite ganhos de peso acima dos estabelecidos, quando comparados apenas com a ingestão de pasto (BARONI et al., 2010). Animais que recebem alimentação de boa qualidade podem apresentar aumento na habilidade para enfrentar as conseqüências adversas do parasitismo. Em segundo lugar, podem apresentar aumento na resistência, limitando o estabelecimento de larvas infectantes, o desenvolvimento e a fecundidade dos nematódeos ou, até mesmo, causando a eliminação dos parasitas já estabelecidos no trato digestório. Por último, o alimento pode afetar diretamente os helmintos ao conter compostos antiparasitários, o que ocorre, por exemplo, com plantas ricas em tanino condensado, influenciando positivamente a sanidade de pequenos ruminantes (OLIVEIRA et al., 2011). Segundo Oliveira 2011 a atividade anti-helmíntica dos taninos condensados pode ser explicada pelo efeito indireto em aumentar a resposta imune de pequenos ruminantes contra parasitos, por meio da proteção de proteínas da degradação ruminal, aumentando sua disponibilidade no intestino delgado. O objetivo deste trabalho foi avaliar o uso de $A$. indica no controle de nematódeos gastrintestinais em ovinos em associação com suplementos protéicos no período seco.

\section{Material e Métodos}

O experimento foi conduzido na Chácara Recreio a 22 km de Cuiabá, no município de Santo Antonio de Leverger - MT, na região da Baixada Cuiabana, entre os dias 04 de Agosto e termino em 30 de Outubro de 2010, correspondendo ao período da seca, sendo 84 dias destinados para avaliação do desempenho animal e 60 dias para avaliação da verminose. A área destinada aos animais para a avaliação do desempenho foi constituída por três piquetes de 0,8 ha cada, formados com a gramínea Brachiaria brizanta cv. Marandu, providos de bebedouros e cochos cobertos. 
Foram utilizados 24 ovinos fêmeas, da raça Santa Inês com idade e pesos médios iniciais de quatro meses e $23,2 \mathrm{~kg}$, respectivamente, dividos em três lotes de oito animais cada, distribuídos aleatoriamente entre os tratamentos, assim constituídos: Suplemento proteico (SP controle), recebendo somente suplemento proteico; Suplemento proteico + óleo de Neem (SP - Óleo) recebendo suplemento proteico e óleo de Neem por via oral; e Suplemento proteico + folha de Neem (SP - Folha), recebendo suplemento proteico adicionado de folhas de Neem. Os animais receberam diariamente o suplemento protéico, enquanto que o óleo e a folha de Neem em intervalos de 15 dias, totalizando quatro tratamentos por 60 dias. Todo experimento foi conduzido segundo a aprovação do comitê de ética em pesquisa (CEP/UNIC) sob o número de protocolo 2011-035.

Para mensurar o desempenho, os animais foram pesados no início e final do experimento sem jejum prévio. Foi realizada a rotação dos animais entre os piquetes experimentais a cada 14 dias, visando reduzir possíveis variações entre a disponibilidade e qualidade da forragem disponível. Uma vez por dia, as 10:00 horas da manhã, os ovinos recebiam $0,100 \mathrm{~kg}$ por animal do suplemento protéico, com composição percentual com base na matéria natural descrito na Tabela 1.

Tabela 1. Composição percentual do suplemento fornecido aos ovinos com base na matéria natural.

\begin{tabular}{lc}
\hline Ingredientes & Quantidade $(\mathrm{kg})$ \\
\hline Farelo de soja & 40,00 \\
Casca do grão de soja & 42,00 \\
Uréia + Sulfato de amônia $(9: 1)^{\text {Mistura Mineral }^{1}}$ & 8,00 \\
\hline Total & 10,00 \\
\hline
\end{tabular}

${ }^{1}$ Mistura mineral comercial para ovinos (Níveis de garantia por $\mathrm{kg}$ de produto: $155 \mathrm{~g}$ de cálcio; $65 \mathrm{~g}$ de fósforo; $115 \mathrm{~g}$ de sódio; $6 \mathrm{~g}$ de magnésio; $175 \mathrm{mg}$ de cobalto; $100 \mathrm{mg}$ de cobre; $175 \mathrm{mg}$ de iodo, $1400 \mathrm{mg}$ de manganês; $42 \mathrm{mg}$ de níquel; $27 \mathrm{mg}$ de selênio; $6000 \mathrm{mg}$ de zinco; flúor (Máx) 650mg).

Fonte: Elaboração dos autores.
No primeiro dia de cada período experimental realizou-se a colheita de amostras da forragem nos diferentes piquetes. Para esta amostragem foram realizadas medições da altura da forragem em 100 pontos por piquete, divididos em duas diagonais (50 pontos por diagonal). Após a medição, os valores foram somados para confecção de uma altura média da forragem por piquete e coletada a forragem a cinco centímetros do solo com um quadrado metálico de $1 \mathrm{~m}^{2}$, em um ponto do piquete cuja a altura fosse igual a média obtida pela medição. Após a coleta, as amostras de cada piquete foram pesadas e homogeneizadas, e a partir dessas retiraram-se duas alíquotas compostas da seguinte maneira: uma para avaliação da disponibilidade total de matéria seca (MS/ha) e outra para análise das disponibilidades por hectare de MS de: folha verde, folha seca, colmo verde e colmo seco, como descrito por Carvalho (2011).

A avaliação da forragem ingerida pelos animais foi realizada utilizando a técnica da simulação de pastejo, coletando-se amostras de pasto em duas linhas diagonais dentro de cada piquete no primeiro dia de cada período experimental, procurando manter sempre os mesmos amostradores, com vistas à diminuição na variabilidade dos resultados, como descrito por Moraes et al. (2005).

Todo o material coletado foi imediatamente congelado em freezer a $-20^{\circ} \mathrm{C}$ para posterior análise de laboratório. Também foram feitas amostragens dos ingredientes usados para a formulação do suplemento e dos suplementos depois de misturados. As amostras dos ingredientes, suplementos e forragens foram analisadas no laboratório de nutrição animal da Universidade Federal de Mato Grosso, para as seguintes variáveis: matéria seca (MS), matéria orgânica (MO), proteína bruta (PB), fibra em detergente neutro (FDN), extrato etéreo (EE) e matéria mineral (MM) realizadas de acordo com as técnicas descritas por Silva e Queiroz (2002). 
Os carboidratos totais (CT) da forragem foram obtidos pela equação proposta por Sniffen, Connor e Van Soest (1992): CHOT $=100-(\% \mathrm{~PB}+\% \mathrm{EE}+$ \%Cinzas). Os carboidratos não fibrosos (CNF) dos suplementos foram obtidos pela equação proposta por Hall (2000): CNF $=100-[(\% \mathrm{~PB}-\%$ PBuréia + $\%$ uréia) $+\% \mathrm{FDN}+\% \mathrm{EE}+\% \mathrm{MM}]$. Os carboidratos não fibrosos (CNF) da forragem foram obtidos pela diferença entre CHOT e FDN.

As análises referentes ao desempenho dos animais experimentais foram conduzidas considerando um delineamento inteiramente casualizado, segundo o modelo estatístico:

$$
\mathrm{y}_{\mathrm{ij}}=\mathrm{m}+\mathrm{t}_{\mathrm{i}}+\mathrm{e}_{\mathrm{ij},} \text {, em que: }
$$

$\mathrm{m}=$ constante geral;

$t_{i}=$ efeito do suplemento $i$, sendo $i=1,2$ e 3 ;

$\mathrm{e}_{\mathrm{ij}}=$ erro aleatório, associado a cada observação, pressuposto NID $\left(0, \mathrm{~s}^{2}\right)$.

Os dados foram analisados por meio de análise de variância e para comparações entre médias, adotou-se o teste de Tukey, sendo todas as análises realizadas por intermédio do programa SAEG UFV (1995), adotando-se o nível de significância de $5 \%$.

No dia 0 os animais do $\mathrm{SP}$ - Controle receberam de forma padronizada no período matutino, somente suplemento protéico (grupo controle), os animais do $\mathrm{SP}+$ óleo de Neem receberam suplemento protéico e $0,25 \mathrm{~mL} / \mathrm{kg}$ de óleo de Neem por via oral e $\mathrm{SP}+$ folha de Neem receberam suplemento protéico adicionado de 0,8 gramas/animal de folha de Neem. A partir do dia 15 os animais em tratamento (SP+óleo de Neem e SP+folha de Neem) receberam acréscimos a cada 15 dias nas quantidades de óleo $(0,5 \mathrm{~mL} ; 0,8 \mathrm{~mL} ; 1 \mathrm{~mL} / \mathrm{kg})$ e folhas $(1,5 \mathrm{~g} ; 2 \mathrm{~g} ; 2,5 \mathrm{~g} /$ animal) de Neem respectivamente, durante um total de 60 dias totalizando-se quatro tratamentos.
Foram realizadas colheitas de amostras de fezes diretamente da ampola retal nos dias de cada tratamento para contagem de ovos por gramas (OPG) segundo a técnica de Gordon e Whithlock (1939) modificada. Realizou-se cultivo de larvas pela técnica de Roberts e O'Sullivan (1949) e a identificação dos gêneros por meio da chave de Keith (1953).

A média aritmética da redução da contagem de ovos nas fezes, para cada grupo tratado (OPGt) foi calculada e comparada com a média do grupo controle (OPGc) segundo Melo (2003) seguindo a seguinte fórmula: $\mathrm{RCOF}=[1-(\mathrm{OPGt} / \mathrm{OPGc})] \times 100$.

\section{Resultados e Discussão}

As disponibilidades de matéria seca total (MST), de folhas verdes (MSFV), de folhas secas (MSFS), de colmos verdes (MSCV) e de colmos secos (MSCS) nas pastagens, em cada um dos períodos experimentais estão dispostas na Figura 1. Foram observados valores médios de disponibilidade de MST, MSFV, MSFS, MSCV e MSCS de 2,01; 0,20; 0,$72 ; 0,21$ e 0,88 ton/ha, respectivamente.

O comportamento dos dados de disponibilidade encontrado está de acordo com os observados por Carvalho (2008), em pastagem de Brachiaria brizanta cv. Marandú. Os baixos valores encontrados para a variável MSFV e MSFS para os meses de setembro e outubro são reflexo da baixa taxa de crescimento das forrageiras no período da seca somados a grande capacidade seletiva dos ovinos, que consomem preferencialmente folhas verdes e secas em relação aos colmos, na tentativa de consumir uma dieta mais adequada as suas exigências nutricionais. 
Figura 1. Disponibilidade de matéria seca total (MST), de folha verde (MSFV), de folha seca (MSFS), de colmo verde (MSCV) e de colmo seco (MSCS) da pastagem Brachiaria brizantha cv. Marandú disponível ao pastejo dos ovinos em função dos meses experimentais.

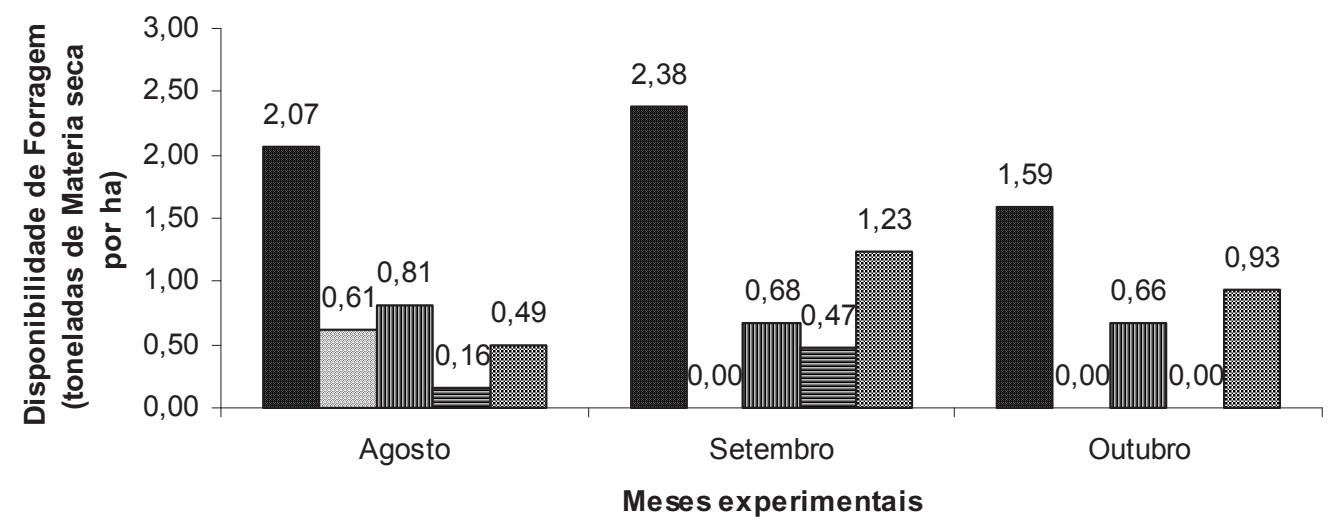

MST $\square$ MSFV m MSFS 㕵 MSCV $\square$ MSCS

Fonte: Elaboração dos autores.

Apesar da disponibilidade de MST mantida ao longo do experimento estar acima do limite mínimo sugerido por Minson (1990) de 2,0 ton/ha, como valor abaixo do qual o consumo pode ser limitado, a forragem usada neste estudo se caracterizava pela elevada proporção de colmos e reduzida proporção de folhas verdes, o que caracteriza uma forragem de baixa qualidade.

Nesse estudo foram observados valores médios de 5,27 \% de PB (Tabela 2), valor este superior aos encontrados por Paulino et al. (2002) e Gomes Junior et al. (2002) de respectivamente 2,52 e 3,96\% PB e mais próximos aos valores encontrados por Carvalho (2008) e Miranda (2008) que analisando amostras de pastejo simulado no período seco, obtiveram médias de 5,49 e 6,11\% $\mathrm{PB}$, respectivamente. Os valores de $\mathrm{PB}$ situaram-se abaixo do mínimo necessário $(7 \%$ PB) para garantir adequada fermentação dos carboidratos estruturais no rúmen (MINSON, 1990).

O teor médio de FDN encontrado para forragem no presente estudo foi de $77,38 \%$, sendo superior aos valores encontrados por Euclides et al. (1998) de $71,70 \%$ em amostras de pastejo simulado e próximas do valor encontrado por Carvalho (2008) de $75,28 \%$. A composição bromatologica do suplemento utilizado está disposta na Tabela 3.

O teor médio de FDN encontrado para forragem no presente estudo foi de $77,38 \%$, sendo superior aos valores encontrados por Euclides et al. (1998) de $71,70 \%$ em amostras de pastejo simulado e próximas do valor encontrado por Carvalho (2008) de 75,28 \%. A composição bromatologica do suplemento utilizado está disposta na Tabela 3. 
Tabela 2. Teores de Matéria seca (MS), matéria orgânica (MO), proteína bruta (PB), fibra em detergente neutro (FDN), extrato etéreo (EE), carboidratos totais (CHOT), carboidratos não fibrosos (CNF) e matéria mineral (MM) em amostras de forragem disponíveis para o pastejo dos ovinos, obtidas via simulação manual de pastejo.

\begin{tabular}{lrrrr}
\hline \multirow{2}{*}{ Itens } & \multicolumn{3}{c}{ Meses experimentais } & \multirow{2}{*}{ Média } \\
\cline { 2 - 4 } & Agosto & Setembro & Outubro & 71,82 \\
MS (\%) & 74,45 & 81,88 & 59,14 & 92,97 \\
MO $^{1}$ & 93,01 & 92,81 & 93,08 & 5,27 \\
PB $^{1}$ & 6,23 & 5,13 & 4,44 & 70,31 \\
$\mathrm{FDN}^{1}$ & 71,37 & 62,2 & 7,36 & 3,5 \\
$\mathrm{EE}^{1}$ & 3,87 & 4,17 & 86,17 & 84,2 \\
$\mathrm{CHOT}^{1}$ & 82,91 & 83,51 & 8,81 & 13,89 \\
$\mathrm{CNF}^{1}$ & 11,54 & 21,31 & 6,92 & 7,03 \\
MM $^{1}$ & 6,99 & 7,19 & & \\
\hline
\end{tabular}

${ }^{1}$ valores expressos na matéria seca.

Fonte: Elaboração dos autores.

Tabela 3. Teores de Matéria seca (MS), matéria orgânica (MO), proteína bruta (PB), fibra em detergente neutro (FDN), extrato etéreo (EE), carboidratos totais (CHOT), carboidratos não fibrosos (CNF) e matéria mineral (MM) no suplemento fornecido aos ovinos em complemento a pastagem, com base na matéria seca.

\begin{tabular}{lc}
\hline Itens & Suplemento Proteico \\
\hline $\mathrm{MS}(\%$ Matéria natural) & 90,72 \\
$\mathrm{MO}^{1}$ & 87,77 \\
$\mathrm{~PB}^{1}$ & 37,05 \\
$\mathrm{FDN}^{1}$ & 57,04 \\
$\mathrm{EE}^{1}$ & 2,19 \\
$\mathrm{CHOT}^{1}$ & 60,77 \\
$\mathrm{CNF}^{1}$ & 3,73 \\
$\mathrm{MM}^{1}$ & 12,23 \\
\hline
\end{tabular}

${ }^{1}$ Valores expressos na matéria seca

Fonte: Elaboração dos autores.

Tabela 4. Valores médios de peso vivo inicial (PV Inicial) e final (PV Final), ganhos de peso total (GP Total), ganho médio diário (GMD), coeficiente de variação em porcentagem (CV\%) e consumo de suplemento pelos ovinos para os diferentes tratamentos experimentais.

\begin{tabular}{lcccc}
\hline \multirow{2}{*}{ Item } & \multicolumn{3}{c}{ Tratamentos } & \multirow{2}{*}{ CV (\%) } \\
\cline { 2 - 4 } & SP - Controle & SP - Óleo & SP - Folha & \\
\hline PV Inicial (kg) & 17,32 & 17,05 & 17,00 & - \\
PV Final (kg) & 20,88 & 19,46 & 19,46 & - \\
GP Total (kg) & 3.56 & 2,41 & 2,46 & 37,27 \\
GMD (kg) & $0,042 \mathrm{a}$ & $0,028 \mathrm{a}$ & $0,029 \mathrm{a}$ & 37,27 \\
Consumo de suplemento (kg/dia) & 0,100 & 0,100 & 0,100 & - \\
\hline
\end{tabular}

Valores seguidos de letras iguais na linha, não diferem pelo teste Tukey a 5\% de significância.

Fonte: Elaboração dos autores. 
Contudo neste estudo, a associação entre a suplementação protéica e o uso da folha e óleo do Neem (SP - Óleo e SP - Folha), não foram capazes de melhorar o desempenho animal mesmo com a diminuição do OPG a partir da terceira quinzena da condução do experimento em relação aos animais que receberam apenas a suplementação proteica (SP - Controle), evidenciando assim a capacidade da suplementação com proteína surtir maiores efeitos sobre o controle da verminose em relação ao uso das associações proteína+folha de Neem e proteína+óleo de Neem.

Segundo Wallace et al. (1999) a queda na qualidade nutricional da dieta leva a uma possível diminuição da digestibilidade e consumo de matéria seca, tornando o ambiente mais propício aos endoparasitos, alem de refletir na capacidade de resistência, pois animais com infecção parasitária seriam mais exigentes nutricionalmente.
Com relação aos tratamentos com o óleo e as folhas de Neem como fitoterápico no controle de endoparasitos, não se evidenciou eficiência significativa na redução de OPG, aumentando em $64 \%$ e $76 \%$ a liberação de ovos nas fezes nos grupos tratados com Suplemento proteico e óleo (SP Óleo) e suplemento proteico e folhas (SP - Folha), respectivamente. $\mathrm{O}$ baixo número de $\mathrm{OPG}$ em todos os grupos pode ser explicado pelo período seco do ano (agosto a outubro) em que foi realizado o experimento. Segundo Vieira et al. (1997), durante a época seca a infecção dos animais é menor devido as larvas e ovos do parasitos presentes no ambiente serem degradados pela ação da radiação solar. Contudo os presentes resultados revelam que houve uma aparente redução, contudo não significativo, do número de OPG após a segunda administração do óleo de Neem (SP - Óleo) a uma concentração de $0,5 \mathrm{ml} / \mathrm{kg}$ do óleo em comparação aos tratamentos $\mathrm{SP}$ - Controle e SP - Folha, visualizado na Tabela 5.

Tabela 5. Resultado do teste de redução da contagem de ovos nas fezes (RCOF) em ovinos mantidos em pastagens de Brachiaria brizantha cv. Marandu no período da seca recebendo Suplemento proteico (controle), suplemento proteico + óleo de Neem e suplemento proteico + folha de Neem.

\begin{tabular}{|c|c|c|c|c|c|}
\hline Dias & $\mathrm{SP}$ - controle & & & & lha \\
\hline Dos & OPG & OPG & RCOPF & OPG & RCOPF \\
\hline Tratamentos & Média* & Média* & $(\%)$ & Média* & $(\%)$ \\
\hline Dia 0 & $1250 \mathrm{a}$ & $1850 \mathrm{a}$ & & $2007 \mathrm{a}$ & \\
\hline Dia 15 & $1121 \mathrm{a}$ & $1214 a$ & -8 & $1692 \mathrm{a}$ & -50 \\
\hline Dia 30 & $735 a$ & $464 a$ & 37 & $1278 \mathrm{a}$ & -74 \\
\hline Dia 45 & $642 a$ & $921 \mathrm{a}$ & -43 & $1135 \mathrm{a}$ & -76 \\
\hline Dia 60 & $592 \mathrm{a}$ & $971 \mathrm{a}$ & -64 & $500 \mathrm{a}$ & 16 \\
\hline
\end{tabular}

Valores seguidos pela mesma letra nas colunas não diferem estatisticamente entre si pelo teste de Tukey a 5\% de probabilidade (p $<0,05)$.

* Média aritmética do número de ovos por grama de fezes dos grupos de cada tratamento.

Fonte: Elaboração dos autores.

Por meio da técnica de coprocultura utilizando a metodológia adaptada de Roberts e O’Sullivan (1950), o gênero Haemonchus sp. foi o mais prevalente, seguido do gênero Trichostrongylus.

Segundo Chagas e Vieira (2007) os estudos investigativos com $A$. indica devem se concentrar na ação biológica do óleo extraído diretamente da semente que possui quantidade maior de azadirachtina que às folhas. As sementes produzem cerca de 4 a 6 gramas de azadirachtina por quilo de semente e $85 \%$ dessa substância é composta pelo isômero AZ-A, considerado o de maior potencial 
anti-parasitário. Enquanto a semente possui aproximadamente $24,85 \mathrm{mg} / 100 \mathrm{~g}$ de AZ-A, as folhas possuem somente $0,59 \% / 100 \mathrm{~g}$ da substância. Dessa maneira o presente estudo comprova a melhor eficiência do óleo de Neem com relação as folhas. As folhas, contudo são zootecnicamente melhores por apresentarem maior facilidade na administração aos animais quando adicionadas juntamente com o concentrado ou suplemento proteico. Porém quando administradas em concentrações elevadas podem ser tornar inviáveis de serem administradas devido aos problemas de palatabilidade. As folhas possuem gosto amargo e os animais tendem a separá-las do alimento quando fornecidas junto com o suplemento, porém esse comportamento não foi visualizado nesse experimento.

Pessoa (2001) ao extrair a azadirachtina das sementes do Neem provocou a inibição de $68 \%$ na eclobilidade de $H$. contortus a uma concentração de 1\%. Ahmed et al. (1994) obtiveram eficácia de 30 a $40 \%$ do extrato aquoso de sementes contra nematódeos gastrintestinais de ovinos. Resultados semelhantes foram visualizados neste experimento com uma eficiência não significativa de $37 \%$ na redução de OPG a uma concentração de $0,5 \mathrm{ml} / \mathrm{kg}$ de óleo de Neem.

O tratamento com fornecimento das folhas de Neem $(0,8 g ; 1,5 g ; 2 g ; 2,5 g$ /animal com intervalo de 15 dias durante 60 dias) reduziu o OPG dos animais em $16 \%$, após o último tratamento a níveis de infecções aceitáveis em ovinos (500 OPG), tal diferença porém não teve significância estatística.

Os presentes resultados foram semelhantes aos obtidos por Macedo et al. (2007), o qual administrou 0,3 ,6 e 9 gramas/folhas/animal por 5 dias consecutivos durante 25 dias, não observando redução da infecção por endoparasitos em ovinos, com OPG dos animais tratados com 6 e 9 gramas de folhas/animal aumentando para média de 3967 e 3433 OPG de fezes respectivamente.
De acordo com estudos de Chandrawathani et al. 2006, os quais trataram ovinos experimentalmente infectados com $H$. Contortus, com 3 gramas de folhas/kg de animal, não houve diferença estatística na redução de ovos de $H$. contortus liberados nas fezes, porém foi observada redução no número de larvas de $H$. contortus na coprocultura nos ovinos tratados com as folhas de Neem em comparação ao grupo controle, comprovando a eficiência das folhas de Neem sobre as larvas eclodidas. Outros autores como Costa, et al. (2006) e Chagas e Vieira (2007) ao administrarem folhas de Neem para ovinos e caprinos respectivamente, $0,1 \mathrm{~g} / \mathrm{kg}$ a $0,2 \mathrm{~g} / \mathrm{kg}$ por 3 meses e $30 \mathrm{~g} / \mathrm{animal} / \mathrm{dia}$ por um período de 28 dias, também não observaram diferença significativa entre os grupos tratados e os grupos controles.

\section{Conclusão}

A administração oral de óleo e folhas de Neem em ovinos fêmeas nas concentrações $0,5 \mathrm{ml} ; 0,8 \mathrm{ml} ; 1 \mathrm{ml} /$ $\mathrm{kg}$ e $1,5 \mathrm{~g} ; 2 \mathrm{~g} ; 2,5 \mathrm{~g}$ /animal respectivamente não foi eficaz no tratamento de nematódeos gastrintestinais de ovinos, enquanto que a suplementação protéica evidenciou redução nos OPG de fezes dos animais mantidos em pastagens de baixa qualidade. $\mathrm{O}$ uso dos derivados do Neem como anti-helmintico carecem de maiores investigações nas concentrações das dosagens por animal, afim de detectar a aplicabilidade desses extratos no controle de parasitos internos de ovinos.

\section{Referências}

AHMED, N. U. Comparative efficacy of modern anthelminthics with that neem seeds against gastrointestinal nematodeoses in sheeps. Bangladeshi Veterinary Journal, Bangladeshi, v. 28, n. 1-4, p. 21-23, 1994.

BARONI, C. E. S.; LANA, R. P.; MANCIO, A. B.; MENDONÇA, B. P. C.; LEÃO, M. I.; SVERTZU, C. B. Consumo e digestibilidade de nutrientes em novilhos suplementados e terminados em pasto, na seca. Arquivo Brasileiro de Medicina Veterinária e Zootecnia, Belo Horizonte, v. 62, n. 2, p. 365-372, 2010. 
CARNEIRO, R. D.; AMARANTE, A. F. T. Seasonal effect of three pasture plants species on the free-living stages of Haemonchus contortus. Arquivo Brasileiro de Medicina Veterinária e Zootecnia, Belo Horizonte, v. 60, n. 4, p. 864-872, 2008.

CARVAlHO, D. M. G. Avaliação bioeconomica da suplementação de bovinos e ovinos em pastagens de Brachiaria brizantha cv. Marandu e Xaraés. 2011. Tese. (Doutorado em Agricultura Tropical) - Universidade Federal de Mato Grosso, Cuiabá.

Fontes de energia em suplementos múltiplos para bovinos em pastejo no período da seca. 2008. Dissertação. (Mestrado em Ciência Animal) Universidade Federal de Mato Grosso, Cuiabá.

CHAGAS, A. S.; VIEIRA, L. S. Ação da Azadirachta indica (Neem) em nematódeos gastrintestinais de caprinos. Brazilian Journal of Veterinary Research and Animal Science, São Paulo, v. 44, n. 1, p. 49-55, 2007.

CHANDRAWATHANI, P.; CHANG, K. W.; NURULAINI, R.; WALLER, P. J.; ADNAN, M.; ZAINI, C. M.; JAMNAH, O.; KHADIJAH, S.; VINCENT, N. Daily feeding of fresh Neem leaves (Azadirachta indica) for worm control in sheep. Tropical Biomedicine, Malasia, v. 23, n. 1, p. 23-30, 2006.

COSTA, C. T. C.; BEVILACQUA, C. M. L.; MACIEL, M. V.; CAMURCA-VASCONCELOS, A. L. F.; MORAIS, S. M.; MONTEIRO. M. V. B.; FARIAS, V. M.; DA SILVA, M. V.; SOUZA, M. M. C. Anthelmintic activity of Azadirachta indica A. Juss against sheep gastrointestinal nematodes. Veterinary Parasitology, Amsterdam, v. 137, n. 3-4, p. 306-310, 2006.

EUCLIDES, V. P. B.; FILHO, K. E.; ARRUDA, Z. J.; FIGUEIREDO, G. R. Desempenho de novilhos em pastagens de Brachiaria decumbens submetidos a diferentes regimes alimentares. Revista Brasileira de Zootecnia, Viçosa, MG, v. 27, n. 2, p. 246-254, 1998.

GOMES JÚNIOR, P.; PAULINO, M. F.; DETMANN, E.; VALADARES FILHO, S. C.; ZERVOUDAKIS, J. T.; LANA, R. P. Desempenho de novilhos mestiços na fase de crescimento suplementados durante a época seca. Revista Brasileira de Zootecnia, Viçosa, MG, v. 31, n. 1, p. 139-147, 2002.

GORDON, H. McL.; WHITLOCK, H. V. A new technique for counting nematode eggs in sheep faeces. Journal of Commnwealth Science Industry Organization, Austrália, v. 12, n. 1, p. 50-52, 1939.

HALL, M. B. Calculation of non-structural carbohydrate content of feeds that contain non-protein nitrogen. University of Florida, 2000. p. A25-A34 (Bulletin, 339).
KEITH, R. K. The differentiation of the infective larvae of some common nematodes parasites of cattle. Australian Journal of Zoology, Austrália, v. 1, n. 2, p. 223-235, 1953.

MACEDO, F. R.; LOUVANDINI, H.; PALUDO, G. R.; MCMANUS, C. M.; PORTO, A. D.; MARTINS, R. F. S.; VIANA, P. G.; NEVES, B. P. Effects of Azadirachta indica on sheep infected naturally with helminthes. American Journal of Animal and Veterinary Sciences, Estados Unidos, v. 2, n. 4, p. 121-126, 2007.

MELO, A. S. F. L.; REIS, I. F.; BEVILAQUA, C. M. L.; VIEIRA, L. S.; ECHEVARRIA, F. A. M.; MELO, L. M. Nematódeos resistentes a anti-helmíntico em rebanhos de ovinos e caprinos do estado do Ceará, Brasil. Ciência Rural, Santa Maria, v. 33, n. 2, p. 339-344, 2003.

MINSON, D. J. (Ed.). Forage in ruminant nutrition. Queensland: Academic Press, 1990. 483 p.

MIRANDA, L. Suplementação de ovinos em pastagem de Brachiaria brizantha cv. marandu durante a época seca: desempenho, comportamento e parâmetros ruminais. 2008. Dissertação. (Mestrado em Agricultura Tropical) Universidade Federal de Mato Grosso, Cuiabá.

MOLENTO, M. B. Resistência de helmintos em ovinos e caprinos. Revista Brasileira de Parasitologia Veterinária, Jaboticabal, v. 13, p. 82-87, 2004. Suplemento 1.

MORAES, E. H. B. K.; PAULINO, M. F.; ZERVOUDAKIS, J. T.;VALADARES FILHO, S. C.; MORAES, K. A. K. Avaliação qualitativa da pastagem diferida de Brachiaria decumbens Stapf., sob pastejo, no período da seca, por intermédio de três métodos de amostragem. Revista Brasileira de Zootecnia, Viçosa, MG, v. 34, n. 1, p. 30-35, 2005.

MOTA, M. A.; CAMPOS, A. K.; ARAÚJO, J. V. Controle biológico de helmintos parasitos de animais: estágio atual e perspectivas futuras. Pesquisa Veterinária Brasileira, Seropédica, v. 23, n. 3, p. 93-100, 2003.

OLIVEIRA, L. M. B.; BEVILAQUA, C.M.L.; MORAIS, S. M.; VASCONCELOS, A. L. F. C.; MACEDO, I. T. F. Plantas taniníferas e o controle de nematóides gastrintestinais de pequenos ruminantes. Ciência Rural, Santa Maria, v. 41, n. 11, p. 1967-1974, 2011.

PAULINO, M. F.; DETMANN, E.; VALADARES FILHO, S. C.; LANA, R. P. Soja grão e caroço de algodão em suplementos múltiplos para terminação de bovinos mestiços em pastejo. Revista Brasileira de Zootecnia, Viçosa, MG, v. 31, p. 484-491, 2002. Suplemento.

PESSOA, L. M. Atividade ovicida in vitro de plantas medicinais contra Haemonchus contortus. 2001. Dissertação. (Mestrado em Ciência Veterinária) Universidade Estadual do Ceará, Fortaleza. 
ROBERTS, F. H. S.; O'SULLIVAN, P. J. Methods for eggs-counts and larval cultures for strongyles infesting the gastrointestinal tract of cattle. Australian Journal of Agricultural Research, Austrália, v. 1, n. 1, p. 99-102, 1950.

SISTEMA DE ANÁLISES ESTATÍSTICAS E GENÉTICA - SAEG. Manual do usuário. Versão 5.1. Viçosa: Universidade Federal de Viçosa, 1995.

SILVA, D. J.; QUEIROZ, A. C. Análise de alimentos: métodos químicos e biológicos. 3. ed. Viçosa, MG: Universidade Federal de Viçosa, 2002. 165 p.

SNIFFEN, C. I.; O'CONNOR, I. D.; Van SOEST, P. J. A net carbohydrate and system for evaluating cattle diets: II. Carbohydrate and protein availability. Journal of Animal Science, Savoy, v. 70, n. 12, p. 3562-3577, 1992.

TAVARES, M. N. B.; BENIGNO, R. N. M.; BITTENCOURT, R. H. F. P. M.; FALESI, I. C.; RODRIGUES, L. F. S.; MOREIRA, V. M. T. S. O uso do nim (Azadirachta indica A. de Jessieu) no controle dos nematóides gastrintestinais de ovino. [2009?]. Disponível em: <http:/www.sovergs.com.br/conbravet2008/anais/ cd/resumos/R0185-1.pdf. $>$. Acesso em: 10 out. 2011.
VELOSO, C. F. M.; LOUVANDINI, H.; KIMURA, E. A.; AZEVEDO, C. R.; ENOKI, D. R.; FRANÇA, L. D.; MCMANUS, C. M.; DELL'PORTO, A.; SANTANA, A. P. Efeitos da suplementação protéica no controle da verminose e nas características de carcaça de ovinos Santa Inês. Ciência Animal Brasileira, Goiânia, v. 5, n. 3, p. 131-139, 2004.

VIEIRA, L. S. Métodos alternativos de controle de nematóides gastrintestinais em caprinos e ovinos. 2007. Disponível em: <http://www.emepa.org.br/revista/ volumes/tca_v2_n2_jun/tca09_metodos.pdf.>. Acesso em: 29 out. 2011 .

VIEIRA, L. S.; CAVALCANTE, A. C. R.; XIMENES, L. J. F. Epidemiologia e controle das principais parasitoses de caprinos nas regiões semi-áridas do Nordeste do Brasil. Sobral, CE: Embrapa/Caprinos, 1997. 49 p. (EMBRAPA/CAPRINOS-MERIAL. Circular técnica).

WALLACE, D. S.; BAIRDEN, K.; DUNCAN, J. L.; ECKERSALL, J. L.; FISHWICK, G.; HOLMES, P. H.; McKELLAR, Q. A.; MITCHELL, S.; MURRAY, M.; PARKINS, J. J.; STEAR, M. J. The influence of increased feeding on the susceptibility of sheep to infection with Haemonchus contortus. Journal of Animal Science, Estados Unidos, v. 69, n. 1, p. 457-463, 1999. 